\title{
Viajes, intermediarios culturales y negociaciones territoriales en larga duración. Amaicha del Valle (Tucumán, Argentina), siglos XIX-XXI
}

\author{
Lorena B. RoDRÍGUEZ \\ Universidad de Buenos Aires - CONICET \\ rodriguezlo@hotmail.com \\ Maité Boullosa Joly \\ Université d'Amiens - CURAPP \\ maite.boullosa@wanadoo.fr
}

Recibido: 14 de agosto de 2013

Aceptado: 18 de septiembre de 2014

\begin{abstract}
RESUMEN
A lo largo de la historia de la Comunidad Indígena de Amaicha del Valle algunas figuras de autoridad realizaron viajes a distintos lugares con el propósito de representar al colectivo en variados temas; uno de ellos fundamental: «asegurar la tierra». Los viajes de estas figuras no sólo los marcaron y transformaron a título individual sino que también, y por diversos motivos, dejaron huella en el devenir del colectivo. Desde este marco, y a partir de un análisis interdisciplinario y de larga duración, el propósito general de este trabajo es repensar la experiencia del viaje como parte de un repertorio de estrategias constitutivo de la reproducción socio-étnica de la comunidad. A tal fin, analizamos los viajes realizados por cuatro líderes de la comunidad en diferentes contextos históricos: décadas de 1800, 1870, 1990 y 2000. Sin descuidar las particularidades de cada momento, personas y traslados en cuestión, ponemos el foco en aquellos aspectos que nos permiten trazar similitudes entre los viajeros y sus viajes a lo largo del amplio rango temporal de estudio. Consideramos las características y trayectorias de cada una de las figuras de autoridad, el impacto que supuso el viaje en términos de legitimidad y construcción personal de poder, y los recursos materiales y/o simbólicos obtenidos-buscados a partir de esos viajes tanto a nivel comunitario como individual.
\end{abstract}

Palabras clave: Indígenas, viajes, territorio, intermediarios culturales, larga duración.

\section{Travels, Cultural Brokers and Territorial Negotiations over Time. Amaicha del Valle (Tucumán, Argentina), 19-21 th Centuries}

\begin{abstract}
Throughout the history of the Indigenous Community of Amaicha del Valle some authorities travelled to different places in order to represent the group for several reasons, the most important being «to secure the land». The voyages these leaders made not only marked and transformed them individually but also, and for several reasons, left their mark on the development of the community. From this framework, and through developing an interdisciplinary and long term analysis, the goal of this work is to rethink the travel experience as part of a repertoire of strategies aimed at the socio-ethnic reproduction of the community. For this purpose, we analyze the trips made by four community leaders in different historical contexts: the decades of 1800 s, 1870s, 1990s and 2000s. Without neglecting the particularities of each moment, people and travels, we focus on those aspects that allow us to draw similarities between travelers and their trips along the temporal range of study. We consider the characteristics and trajectories of the ethnic leaders, the impact that their voyages had in terms of legitimacy and the personal construction of power, as well as the material and symbolic resources they searched for and obtained from those trips, both at community and individual level.
\end{abstract}

Key words: Indigenous, travels, territory, cultural brokers, long term.

Sumario: 1. Introducción. 2. Contextualización general del caso de la Comunidad de Amaicha del Valle. 3. Viajes, trayectorias de poder y recursos: trazando semejanzas entre las autoridades étnicas. 4. Palabras finales. 5. Referencias documentales. 6 . Referencias bibliográficas. 
«o sea siempre hemos buscado, más allá de lo que esté pasando actualmente, pero siempre lo que se busca, por lo menos de manera simbólica, es la cuestión de asegurar la tenencia de la tierra [...] sin duda, los caciques han tenido mucho poder en cuanto al conocimiento de los instrumentos que pueden dar garantía de defender el territorio» (Comunero de Amaicha del Valle, enero de 2013).

\section{Introducción}

Como puede leerse en la cita que encabeza este trabajo, la cuestión de «asegurar» la tenencia de la tierra ha sido fundamental en el devenir de la Comunidad Indígena de Amaicha del Valle (provincia de Tucumán, Argentina). Tal como lo destaca el comunero entrevistado, los caciques o autoridades étnicas han ocupado un lugar fundamental en dicho sentido. En el caso de Amaicha, el problema de la tierra, el rol de los caciques y los procesos de construcción de identidad y memoria han sido temáticas abordadas, desde una perspectiva histórica o antropológica, por diferentes autores ${ }^{1}$. Sin embargo, un tema que no ha sido relevado hasta el momento, que está vinculado estrechamente y que podría contribuir a repensar tales problemáticas, es el del viaje (o los viajes). A lo largo de la historia de la comunidad algunos líderes o figuras de autoridad realizaron viajes a distintos lugares con el propósito de representar al colectivo en variados temas; uno de ellos fundamental: «asegurar la tierra». Como veremos en este artículo, los viajes de estas figuras no sólo los marcaron y transformaron a título individual, sino que también, y por diversos motivos, dejaron huella en el colectivo.

Desde este marco, el propósito general de este trabajo es repensar la experiencia del viaje como parte de un repertorio de estrategias constitutivo de la reproducción socio-étnica de la comunidad. A tal fin, analizaremos los viajes realizados por cuatro líderes de la Comunidad Indígena de Amaicha del Valle en diferentes contextos históricos y coyunturas políticas: décadas de 1800, 1870, 1990 y 2000. Sin descuidar las particularidades de cada momento, personas y traslados en cuestión, haremos foco en aquellos aspectos que nos permitan trazar similitudes entre los viajeros y sus viajes a lo largo del amplio rango temporal de estudio. En tal sentido, consideraremos las características y trayectorias de cada una de las figuras de autoridad, el impacto que supuso el viaje en términos de legitimidad y construcción personal de poder, y los recursos materiales y/o simbólicos obtenidos-buscados a partir de esos viajes tanto a nivel comunitario como individual. Asimismo, especialmente en relación con contextos históricos más contemporáneos, incorporaremos al abordaje del viaje la dimensión misteriosa que el mismo puede conllevar. En algunos casos, esta dimensión se transforma en algo ponderado positivamente y, en otros, en el vector de sospechas y conflictos.

El análisis del viaje que nos proponemos realizar en este trabajo en tanto fenómeno complejo con sus diferentes aristas y temáticas asociadas (liderazgos políticos, identidad y memoria colectivas, reproducción socio-étnica, etc.), se sostiene en la

1 Remitimos, a modo de ejemplo, a los trabajos de Cruz (1990-92), Isla (2002), Sosa y Lenton (2009) y Steiman (2011), entre otros. 
interpretación del mismo no sólo como una forma de obtener recursos materiales sino también como una verdadera peregrinación política y simbólica que permite, no sin conflictos, instituir mecanismos de representación, entablar alianzas externas, aunar intereses diversos en pos de una unidad socio-política así como reafirmar valores y creencias fundamentales que dan marco a la posibilidad de una existencia colectiva (Pacheco de Oliveira 1998).

Por otra parte, encuadramos nuestro análisis dentro de los estudios que parten de la noción de «passeurs culturels» (intermediarios culturales) para dar cuenta de aquellos agentes sociales que se encuentran en la interfase entre diferentes universos geográficos y sociales, conocen y manejan los lenguajes respectivos y se transforman, de ese modo, en el puente entre la sociedad más amplia y su comunidad. Este concepto nos parece de suma utilidad pues nos brinda el soporte para cruzar y articular diferentes épocas y situaciones ${ }^{2}$. A nuestro entender, las distintas autoridades étnicas de Amaicha del Valle sobre las que haremos foco en esta oportunidad, cada una en su propio contexto, pueden ser definidas como «passeurs culturels».

En términos metodológicos, el análisis aquí propuesto es el resultado de una mirada procesual, de larga duración e interdisciplinaria que recupera las posibilidades (y también las limitaciones) de las metodologías del trabajo etnográfico y del quehacer histórico. Es por eso que, a partir de nuestras experiencias particulares desde los campos de la antropología social y de la antropología histórica, de los datos recogidos en diferentes trabajos de campo realizados desde el año 2001 y de nuestras exploraciones en distintos archivos históricos, no sólo analizaremos el viaje como un elemento más -entre otros- que nos permite comprender el devenir de un colectivo, sino que cerraremos este texto con una reflexión de tipo metodológica que nos conduzca a repensar nuestros abordajes y responder preguntas o continuar planteando problemas de investigación de manera compleja.

\section{Contextualización general del caso de la Comunidad de Amaicha del Valle}

En épocas pre-hispánicas los valles Calchaquíes estuvieron habitados por una numerosa población, denominada genéricamente en los documentos coloniales como «diaguita», que efectivamente estaba compuesta por una heterogénea cantidad de poblaciones de habla kakana, quienes aunque habrían compartido algunas pautas culturales se mantenían como unidades políticas independientes con capacidad para

2 La noción de «passeurs culturels» ha sido desarrollada en los trabajos de Berta Ares Queija y Serge Gruzinski (1997) a propósito de los agentes sociales que favorecieron las transferencias y el diálogo entre Europa Mediterránea, América y Asia desde el siglo XVI al XIX. Para contextos más contemporáneos, el término «passeur» ha sido igualmente empleado por Jean-Pierre Olivier de Sardan (1995) para dar cuenta de los agentes que jugaron un rol de mediadores en el marco de diferentes proyectos de desarrollo. A diferencia de este autor, Mónica Martínez Mauri -en un estudio sobre las interacciones entre los kunas de Panamá y las Naciones Unidas en las últimas décadas- ha señalado la pertinencia de utilizar para períodos recientes y situaciones interétnicas el concepto de «passeur culturel» (en los términos de Queija y Gruzinski), en tanto que a través del mismo puede darse cuenta del proceso de hibridación cultural implicado en estos casos. Desde este marco y para Amaicha del Valle, puede consultarse el trabajo de Maité Boullosa-Joly (2006) respecto al rol de ciertos militantes indianistas en la última década. 
confederarse ante riesgos comunes (Lorandi y Boixadós 1987-88). La conquista española de estos valles fue muy particular y se logró tras un intenso proceso de luchas, tensiones y resistencias que duraron más de 130 años (conocidas como «Guerras Calchaquíes», finalizadas hacia 1665) y que resultaron en el proceso de «desnaturalización»; esto es, el traslado forzoso de varias unidades socio-políticas a diversos lugares para ser encomendadas de manera inmediata.

El caso de los «amaichas», etnónimo con que los españoles denominaron-reconocieron a un grupo de indígenas asentados en la actual quebrada de $\mathrm{Amaicha}^{3}$ y sus alrededores (ver Figura 1), si bien se enmarca en aquel contexto general, presenta características peculiares. Por un lado, porque aunque fueron tempranamente reducidos a pueblo en la llanura tucumana, en los alrededores de lo que hoy es la localidad de Bella Vista (es decir antes de las «campañas de pacificación» del gobernador Mercado y Villacorta de 1659 y 1664) y sirvieron intermitentemente a su encomendero, participaron igualmente en el último levantamiento calchaquí. Los autores señalan que, como consecuencia de una actitud ambivalente, si bien terminaron de ser desnaturalizados al finalizar las guerras, también recibieron tierras en sus antiguos asientos vallistos, otorgamiento que en 1716 habría quedado legitimado por una Cédula Real (Cruz 1997). Por otro lado, y más allá del otorgamiento de esta Cédula, porque los «amaichas» emprendieron continuos retornos hacia el valle Calchaquí, delineando una original estrategia del tipo «doble domicilio» que, como señala Cruz (s.f.), pudo haberlos dejado en una mejor situación que a la mayoría de los desnaturalizados para mantener su autonomía y hacer frente a las presiones impuestas por el sistema colonial. De hecho, entre fines del período colonial y los primeros años republicanos, los «amaichas» no sólo habían sostenido el vínculo entre el espacio calchaquino y el de la reducción en el llano, sino que reclamaban formal y jurídicamente tierras en ambos espacios, una reclamación que prosperaría -aunque mucho tiempo después- en el caso de las tierras en Calchaquí ${ }^{4}$.

A nuestro entender, el «aseguramiento» de las tierras vallistas y la reproducción colectiva se sostuvo en el rol que algunos actores sociales desempeñaron en diferentes momentos históricos. En la coyuntura conflictiva de fines del siglo XVIII y principios del XIX, en que una familia poderosa de Salta de apellido Aramburu pretendió

3 Existe evidencia arqueológica de que la quebrada de Amaicha (porción tucumana del valle Calchaquí) habría sido recurrentemente ocupada por grupos humanos con una gran profundidad temporal desde el período Formativo, pasando por el de Desarrollos Regionales, así como en el momento Incaico (Sosa 1999; Rivolta 1999; Somonte 2004). Lógicamente, no puede establecerse relación directa o lineal entre poblaciones ubicadas en períodos temporales tan distantes. Aquí, retomamos la historia de los «amaichas» una vez encomendados y, particularmente, luego de finalizadas las Guerras Calchaquíes. Siguiendo a Wachtel (2001) entendemos que fue a partir de estos procesos que se crearon o recrearon unidades étnicas (lo que después conoceremos como «comunidades indígenas») cuyos límites empezaron a ser los de los pueblos de reducción.

4 Recordamos aquí que mientras la comunidad de Amaicha en el valle puede rastrearse en diferentes documentos durante todo siglo XIX e incluso hasta el día de hoy, la última referencia encontrada para el pueblo de Amaicha en el llano es un expediente de 1857 en que se lo denuncia como vaco (AHT, 1857). Rodríguez (2010) ha interpretado que a fines de la colonia el pueblo de indios de Amaicha inició una profunda transformación que dio paso a un verdadero proceso de etnogénesis que, finalmente, derivó en la fisión formal de la entidad «pueblo de Amaicha» (el pueblo del valle y el del llano). Si el vínculo entre el llano y el valle y entre quienes allí habitaban se mantuvo en el siglo XIX -o más allá de él-o si la reclamación paralela y, en particular, de las tierras vallistas fue parte de una estrategia consensuada entre ambas entidades, es algo que por el momento no puede responderse con certeza. 
Figura 1: Mapa de la provincia de Tucumán y Amaicha del Valle. Fuente: Instituto Geográfico Nacional de la República Argentina.

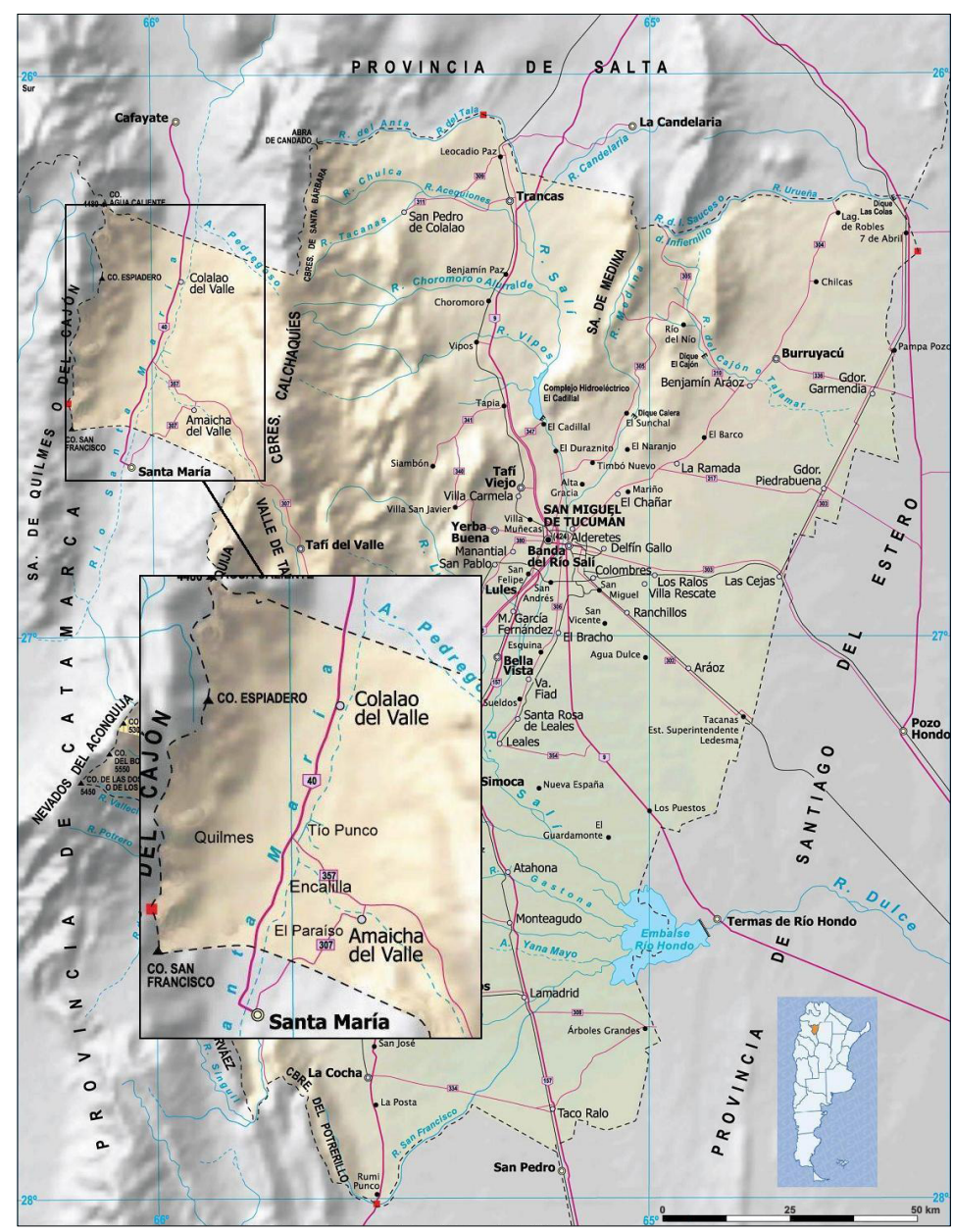

avanzar sobre el territorio comunal, se destacó la figura de don Lorenzo Olivares, por entonces el alcalde cobrador del tributo del pueblo de indios de Amaicha. Don Lorenzo no sólo denunció el maltrato ejercido por la familia Aramburu sobre su persona y otros integrantes del pueblo, sino que inició y encabezó un largo pleito, viajando hasta la Audiencia de Buenos Aires (ca. 1800) a reclamar la propiedad de las tierras disputadas en el valle Calchaquí, constituyéndose él y su «hazaña»en mojón temporal que quedaría en la memoria colectiva. Alejandro Mamaní, uno de los testigos que declaró en el juicio en 1844, dijo «que Olivares se fue a la Audiencia de Buenos Aires y de allí vino ganándole el pleito: que este suceso fue el primero, que tuvo lugar entre Aramburu y los indios, y que ocurrió pocos años antes de la revolución de la independencia, y que lo sabe por que él vivía entonces en Amaicha con su mujer» (AHT, 1845, f. 48).

Hacia 1872, en una nueva coyuntura conflictiva en que el gobierno provincial había dictaminado se pusiese en posesión de las tierras en disputa a Sigifredo Brachieri (segundo esposo de Celestina López, viuda de José Antonio Aramburu), el apoderado 
de la comunidad, don Juan Pablo Pastrana, realizó un nuevo viaje a Buenos Aires y se presentó ante el poder ejecutivo nacional para solicitar que éste interviniera en el antiguo conflicto por las tierras vallistas a fin de que los indígenas de Amaicha no fueran desalojados de las mismas:

«he venido desde mi residencia apoderado de un gran número de convecinos para pedir protección á V.E. del desalojo que se trata de hacer de los que vivimos allí desde tiempo inmemorial, como tributarios de las poblaciones de Encalilla y Amaicha y Tío Punco y que un señor Aramburú y sus descendientes han pretendido desalojarnos y muy al principio de este siglo el cacique y juez de estos lugares don Lorenzo Olivares se costeo a esta ciudad para entablar la cuestión ante la Real Audiencia en la que triunfó completamente pues se ordenó que los habitantes que habian alli no fuesen desalojados y que se respetasen los derechos que tenían adquiridos de conformidad con cédulas reales que ordenaban, al dar mercedes, salvar las poblaciones y derechos adquiridos por los indígenas y, posteriormente, según la situación del país en la guerra civil han intentado también despojarnos, pero nunca lo han conseguido porque no tenían justos títulos y porque debían respetar las leyes existentes; sin embargo, últimamente los tribunales de Tucumán han ordenado que se nos desaloje, y es por eso que me he venido a buscar el expediente que siguió Olivares, pero a pesar de las grandes diligencias que he hecho, no he podido conseguirlo, que sin duda lo habrán hecho extraviar maliciosamente y es entonces que he decidido venir a implorar la protección de V.E. para que nos proteja en los justos derechos que tenemos» (AHT, 1872, fs. $131 v$. a 132v; el destacado es nuestro).

En este fragmento puede observarse cómo varias décadas después del suceso, el viaje hasta la Audiencia de Buenos Aires - ubicado temporalmente a principios del siglo XIX-, el objetivo del mismo - centrado en resguardar las tierras colectivas- y la figura de Lorenzo Olivares -como cacique y juez del lugar- son recordados por el apoderado de la comunidad, Juan Pablo Pastrana. Lo interesante del caso es que Pastrana, como voz de sus «convecinos», no sólo recuerda estos hechos sino que les da entidad al inscribirlos dentro de una presentación formal ante las autoridades del poder ejecutivo nacional y como argumento de protección de las tierras en peligro. Más importante aún es que el propio Pastrana, reclamando ante las autoridades nacionales en Buenos Aires, parece haber reproducido en acción (y no sólo discursivamente) el «peregrinaje» de Olivares para reencontrarse con el expediente abierto por éste último y evitar, en consecuencia, el desalojo dictado por el gobierno tucumano. Si bien no conocemos detalles acerca de cómo siguió el trámite judicial en los años inmediatamente posteriores a las gestiones de Pastrana, sí sabemos que en 1892 se produjo un hecho importante en relación al «aseguramiento» de las tierras de la comunidad: la protocolización de la Cédula Real de 1716 (AGPT, 1892, fs. 1427-28). Esto significa que la misma cobraría a partir de entonces entidad legal en el Estado provincial, constituyéndose así en el resguardo jurídico que finalmente, y como veremos luego, posibilitaría la escrituración de esas tierras a nombre de la comunidad indígena de Amaicha del Valle. Por otra parte, el hecho de haber logrado la protocolización quedaría en la memoria colectiva como resultado de la «hazaña» realizada por Juan Pablo Pastrana cuando viajó hasta Buenos Aires. En 1971, el periodista Julio Ardiles Gray, con base en el relato que le hizo un comunero, escribió: 
«ante la posibilidad de que sus títulos posesorios se discutieran, decidieron enviar a Buenos Aires a un indio como de unos 70 años. Viajó a pie para pedir al Superior Gobierno de la flamante República Argentina una copia legalizada de la Real Cédula de 1716. Cuando regresó con ella, sus pares le obsequiaron en pago una extensión de tierra que fue origen de El Paraíso, donde aún viven descendientes de Juan Pablo Pastrana, el actor de la hazaña» (Ardiles 1971: 8-9) .

Una descendiente del propio Pastrana señalaba al respecto:

«yo he tenido un tío, el abuelo dice se llamaba Pedro Pastrana y el otro el hermano, se llamaba... este... [...]Pastrana y el otro se llamaba Juan Pablo Pastrana y hace mucho dicen que han sido sancarleños y han venido ya y esos tres Pastrana dicen que se habían ido a Buenos Aires y allí de Encalilla viven allá, allá donde pasa el [...] se ubica usted?, Encalilla allí del puente de Quilmes pa' este lao donde están esas fincas, claro. Ahí dicen que ellos se han ido, que han andao como 5 o 6 meses pa' llegar a Buenos Aires, se iban a caballito, trecho de a pié, y que llevaban [...] de cosas de aquí nomás lo que se cosechaba el trigo, el maíz, el patay, carneaban una vaca o cabra, hacían charqui mucho llevaban pa' comer en el camino porque no había nada por el que iban y así han llegao, han llegao y han hecho las diligencias por la comunidad, y ya han hecho las diligencias pa' la comunidad de ellos los 3 y de esa manera nos han donado con la comunidad de ellos, por eso somos comuneros , de esa andanza...» (María Magdalena Pastrana, julio de 2002).

Ahora bien, aunque la protocolización de la Cédula en 1892 constituyó un hito fundamental en el resguardo de la tierra, que alivió momentáneamente las tensiones en torno a ella, no sería hasta muchos años después que la misma lograría escriturarse. Aquí entra en escena una nueva figura que ocupará un lugar destacado en tal proceso: Miguel Pastrana, quien en su doble función de delegado comunal (funcionario del Estado) y de cacique, logró en 1995 la escrituración de las tierras de la comunidad ${ }^{6}$. En su testimonio explica que cuando en 1983 obtuvo por primera vez el cargo de delegado creía que la tierra era de la comunidad. Sin embargo, en esa época descubrió que esto no era así, pues la gestión de un cacique anterior había autorizado al poder ejecutivo provincial la entrega de títulos individuales a los comuneros y que, además, los campos comunes habían pasado a ser tierras fiscales (Ley 4400 del 26/12/1975). Para recuperar el titulo de los campos comunes y transformar el estatus de tierras fiscales, Miguel Pastrana inició una serie de gestiones a fin de modificar los artículos 2 y 3 de la citada ley. En 1986, y luego de trabajar conjuntamente con personas cercanas al poder provincial, logró la modificación deseada con la Ley 5758 (9/4/1986) por la que, según él, el gobierno se obligaba a entregar título a la comunidad y no a los comuneros individualmente. De todas formas, a pesar de la modificada ley, la escrituración llegaría casi diez años después. M. Pastrana explica que el hecho de haber sido a la vez delegado comunal y cacique fue lo que le permitió hacer escriturar las tierras en 1995 y, luego de obtener la personería jurídica como comunidad indígena

\footnotetext{
5 El texto de origen es un extracto de una entrevista periodística realizada por Julio Ardiles Gray a un comunero de Amaicha -don Marcos Juan Rodríguez Espada- en la que relató la historia de la comunidad y de su lucha por la tierra.

6 Escritura Pública No 32 del 1ro de marzo de 1995.
} 
a nivel nacional ${ }^{7}$, que se inscribieran finalmente como tierras comunitarias (indivisibles, no sujetas a gravados impositivos ni enajenables). Según sus propios términos, se sirvió de su función pública como trampolín. Explica que trabajó con varios políticos de la provincia, que hizo muchos trámites, a la vez en Tucumán (en el gobierno provincial) y en Buenos Aires en el Instituto Nacional de Asuntos Indígenas (INAI) y en la Asociación Indígena de la República Argentina (AIRA) para hacer adelantar sus reclamaciones. Nos describe su pelea y esos viajes hechos muchas veces con sus propios fondos.

De todas formas, aunque M. Pastrana dice haber logrado lo que más quería que era «asegurar la tierra», el problema del territorio parece no haber terminado en Amaicha con sus gestiones. Una de las dificultades que él señala actualmente se refiere a la entrega de tierras de la comunidad a gente no comunera: «ya no hay ningún, ningún, como digo, reparo en decir no! esto es nuestro, cómo habrán vivido, habrán pasado nuestros mayores, con sangre, sudor y lágrimas para defender esto para que ahora lo regalemos así, le acabo de contar toda la que me tocó vivir para sacar la escritura (...)» (Miguel Pastrana, enero de 2013). Paradójicamente, uno de sus oponentes políticos atribuye a M. Pastrana, entre otras cosas, una desinteligencia en el manejo del reparto de las tierras durante sus mandatos previos. Este opositor es Eduardo Nieva, actual cacique de la comunidad y otra de las figuras que consideramos relevante en el devenir del colectivo amaicheño.

El abogado Nieva se inserta en una coyuntura diferente en la historia de la comunidad. Escrituradas las tierras, sus propósitos parecen haberse orientado en dos direcciones. Por un lado, luchar contra Miguel Pastrana, acusado de malversación de fondos y, por otro, defender los valores y la cosmovisión indígenas. Si bien Nieva se traslada a Buenos Aires para seguir sus estudios universitarios y en paralelo va descubriendo la causa indígena («y allí donde me fui preparando, empecé a conocer sobre la causa indígena... conocí gente que estaba en la lucha ya de la causa indígena»), el viaje que lo marcará a fuego será el que realice a Washington en 1997 luego de obtener una beca en la Organización de Estados Americanos (OEA). En sus propias palabras: «y de Bs.As. pasar a Washington y aprender a mirar el mundo de ahí» (Eduardo Nieva, noviembre de 2002). Pero no sólo aprendió a mirar al mundo y a Amaicha desde allí, sino que se propuso desde ese momento capitalizar su viaje colectivamente enseñando a los comuneros lo aprendido en la escena del derecho indígena internacional. Retomaremos y profundizaremos en las trayectorias personales de Nieva y de las otras autoridades étnicas en el apartado siguiente.

\section{Viajes, trayectorias de poder y recursos: trazando semejanzas entre las autoridades étnicas}

Presentados de manera general los líderes, algunos de los viajes realizados y las coyunturas específicas en que los mismos tuvieron lugar, en este apartado pretendemos

\footnotetext{
7 En el año 1994 se realizó una reforma de la Constitución Nacional a partir de la cual el Estado reconoce la preexistencia étnica de las poblaciones indígenas y diferentes derechos como la posesión y propiedad comunitarias de tierras. En la provincia de Tucumán son 18 las comunidades indígenas -adscritas a los pueblos diaguita y lule- a las que hasta el presente el Estado nacional ha registrado como tales, otorgándoles su personería jurídica a través del Instituto Nacional de Asuntos Indígenas (INAI).
} 
hacer foco en algunas características que, a nuestro entender, nos permiten trazar ejes comparativos y similitudes entre las autoridades étnicas. Uno de los aspectos a destacar se refiere al perfil y trayectoria de cada una de ellas. Un actual comunero sintetiza, en sus palabras, una de las características fundamentales que describe a quienes se transforman en líderes. Refiriéndose al poder que aún hoy tiene la palabra escrita en Amaicha dice: «la desconfianza hacia el papel, es un elemento de coacción, digamos, la cuestión escrita, sigue siendo creo en Amaicha, por eso confiamos en quienes nos guien, y bueno los que sepan de leyes, un abogado...» (Mario Quintero, enero de 2013). Es decir, manejar la palabra escrita y, de la mano de eso, conocer los resortes legales se transforman en elementos nodales en la configuración de un líder. En tal sentido, podemos afirmar que las cuatro autoridades que realizaron viajes, en distintos momentos y a distintos lugares según cada contexto histórico, cumplían con tales requisitos.

En el caso de Lorenzo Olivares, que entre fines del siglo XVIII y principios del XIX, había sido designado alcalde cobrador de tributo, sabía leer y escribir; al menos así puede deducirse de los recibos de pago del tributo que firmó a cada tributario y que constan en uno de los expedientes del pleito por las tierras vallistas (AHT, 1845, 21 de mayo). Asimismo, es evidente que tenía conocimiento del aparato jurídico y del sistema legal en vigencia. No sólo había iniciado la disputa legal en Tucumán cuando denunció frente a las autoridades capitulares a don Nicolás de Aramburu por la usurpación de los terrenos de Calchaquí (AHT, 1796, fs. 224 a 226), sino que un tiempo después, y seguramente no hallando una respuesta satisfactoria por parte de dichas autoridades, se dirigió a la flamante Audiencia de Buenos Aires para continuar la reclamación ${ }^{8}$.

Juan Pablo Pastrana, por su parte, también sabía leer y escribir y conocía perfectamente los mecanismos judiciales del momento. Como hemos visto, al igual que Olivares y ante la respuesta negativa del gobierno provincial, se había trasladado hasta Buenos Aires a solicitar al gobierno nacional intervención en el asunto de las tierras disputadas por la familia Aramburu y sucesores (Encalilla), utilizando una retórica estratégica: republicana y oficial aunque, a la vez, impregnada de los resabios coloniales (cf. Rodríguez 2009). Como apoderado ${ }^{9}$ de la comunidad, Pastrana intervenía también en otros asuntos relacionados con el problema de las tierras colectivas y los límites de las mismas ${ }^{10}$ y hasta recibía instrucciones del mismísimo gobernador de la provincia para encargarse de la vigilancia de esa frontera. Más interesante aún resulta

\footnotetext{
8 Siguiendo a Tell (2010), entendemos que es probable que la creación de la Real Audiencia de Buenos Aires a fines del siglo XVIII -más cercana y compuesta mayormente por funcionarios ilustrados, comprometidos con los intereses de la Corona y distanciados de los poderes regionales o locales- haya ofrecido a las poblaciones indígenas del Noroeste argentino (NOA) oportunidades concretas de realizar demandas frente a ese tribunal y generar así verdaderos espacios de disputa.

9 Algunos autores interpretan que luego del ocaso colonial y al ser eliminadas las figuras del cacique y del protector de naturales, las comunidades indígenas - presionadas por un nuevo sistema jurídico que instituía la representación personal e individual frente a la ley- iniciaron el proceso de nombramiento de nuevas autoridades: los apoderados. Mendieta Parada (2006), incluso afirma para el caso boliviano que estas nuevas figuras recrearán las antiguas autoridades étnicas de intermediación colonial.

10 Por ejemplo, a lo largo del año 1881, Pastrana intervendrá en un conflicto territorial entre la comunidad y don Justo Rueda (vecino de Santa María, Catamarca), conflicto que tendrá una repercusión importante pues el mismo remitía a un problema más amplio: el de los límites provinciales entre Tucumán y Catamarca y las
} 
el hecho de que, como se indica en un expediente judicial, se haya desempeñado como juez de paz de la zona (AHT, 1882).

El caso de Miguel Pastrana en la segunda mitad del siglo XX es un poco distinto pero tiene también, en ese contexto histórico, ciertas habilidades particulares que pueden compararse a los líderes del siglo XIX y que pueden explicar su papel de dirigente en Amaicha durante 20 años. En cuanto a su historia personal, nació en Santa María de una madre santamariana y de un padre amaicheño y allí vivió hasta los 8 años antes de instalarse en Amaicha donde completó la escuela primaria. A los 14 años se trasladó a San Miguel de Tucumán para trabajar en la construcción, formando parte de la Unión Obrera de la Construcción de la República Argentina (UOCRA). Al regresar a Amaicha, a los 22 años, ingresó a la repartición pública, a la Delegación Provincial del Agua y ahí fue delegado gremial durante muchos años. Como consecuencia de su trabajo como delegado, M. Pastrana debía realizar constantes viajes. Este hecho, sumado a su militancia en el Partido Justicialista (también llamado Partido Peronista o Peronismo), le valió el ser signado como subversivo durante la última dictadura militar en Argentina (1976-1983). Lo explica en una entrevista realizada en enero 2013: «a mí me consideraron en ese momento correo de la subversión porque yo vivía viajando, era delegado gremial y me mandaban muchas veces a cursos de capacitaciones políticas y gremiales en distintas provincias». En 1976 llegó a estar desaparecido por seis meses; en su relato cuenta cómo lo liberaron y cómo continuaron persiguiéndolo al volver después a Amaicha. Describe ese período como un calvario y agrega: «si yo no hubiera llevado en la sangre lo de la política no hubiera vuelto nunca más». Con el retorno de la democracia, M. Pastrana volvió a militar activamente y así fue como ganó por primera vez la elección de delegado comunal en 1983, sosteniéndose en el cargo por tres períodos consecutivos y ocupando el mismo nuevamente luego de las elecciones de agosto de 2011 y hasta el día de hoy.

Como los otros líderes del siglo XIX, Miguel Pastrana sabe leer y escribir; por supuesto este hecho no es tan original ni relevante en la década de 1970, gracias a la escolarización masiva en Argentina, sobre todo a través de la escuela primaria ${ }^{11}$. Pero su trayectoria previa como delegado gremial, sus viajes a distintas provincias y su militancia política le dieron una cierta habilidad en la gestión de la comuna cuando fue elegido delegado comunal en 1983 y, posteriormente, cuando a principios de la década de 1990 fue elegido como cacique. Por otra parte, esa posición de cacique de Amaicha le permitió ser invitado a los Naciones Unidas en el 1998 como representante indígena argentino en los Grupos de Trabajo de los Pueblos Autóctonos (GTPA). Esos lazos políticos a nivel regional, nacional e internacional dieron a Pastrana muchos apoyos externos y la capacidad de movilizar fondos o proyectos de desarrollo para su comunidad. Asimismo, el hecho de haber «asegurado las tierras» le dio reconocimiento de parte de los amaicheños y también mucho poder. Esto puede

\footnotetext{
jurisdicciones correspondientes a cada una de ellas. Véase al respecto: AHT, 1881, fs.682, 683, 684, 685, 687 y $687 \mathrm{v}, 688,689$ y $689 \mathrm{v}, 690,691$.

11 Mario Quinteros, como hemos visto, sostiene igualmente que el hecho de saber leer y escribir es algo que aún hoy tiene cierto peso «...digamos que el cura Valverde con la cédula, digamos en el Perú, en Cajamarca, es decir, tenemos el papel, es decir, claro, es obvio la gente que no no no está acostumbrada a leer, que le cuesta leer es muy difícil que diga ché cómo funciona esto? No me están haciendo meter la pata?...».
} 
explicar el apoyo del que se benefició después del año 2000, cuando fue acusado de malversación de fondos. En muchos testimonios de esa época, M. Pastrana era bien ponderado como artífice de haber ganado las tierras y aun hoy, en el 2013, muchos testimonios de ancianos sostienen esta idea ${ }^{12}$. De todas formas, hay que destacar que M. Pastrana fue muy contestado por una parte de sus oponentes políticos (no peronistas) así como por una parte de la nueva generación que había migrado y que había vuelto al pueblo. En efecto, en el año 2002, en plena crisis, muchos amaicheños jóvenes que previamente habían migrado a San Miguel o a Buenos Aires, volvieron al pueblo con la esperanza de poder vivir en mejores condiciones de las que les ofrecía la ciudad. En Amaicha, esos migrantes, en su calidad de «comuneros», podían beneficiarse por lo menos de una parcela de tierra y de la esperanza de poder empezar de nuevo en un lugar donde no se necesitaba tanto dinero para poder vivir. Muchos de los que volvieron tenían un nivel de formación escolar o profesional más elevado que el promedio de los lugareños y no estaban tan sujetos a las relaciones de dominación locales; disponían de un poder de contestación mucho más fuerte. El caso más ejemplar fue el de Eduardo Nieva.

E. Nieva nació en Amaicha del Valle, fue criado por un abuelo, don Raymundo Silva, un cacique muy estimado en Amaicha. A los 12 años, Nieva se fue a Santa María (Catamarca) para realizar estudios secundarios y allí comenzó a trabajar para poder financiar sus estudios. En 1989 se trasladó a Buenos Aires y entró en la Facultad de Derecho, donde por primera vez tuvo conocimiento acerca del derecho indígena. Nieva contaba en una entrevista cómo volvía cada verano a Amaicha para compartir todo lo que aprendía en Buenos Aires con los jóvenes del pueblo. De la toma de conciencia de la necesidad de valorar su propia cultura nació la escuela Amauta, ese emprendimiento cultural que tuvo tanto éxito en Amaicha al final de los años 90 y principios de la década siguiente. Una vez recibido de abogado, Nieva ganó la beca ya referida que lo llevó hasta Washington. A partir de ese viaje, logró un reconocimiento a nivel internacional y fue posteriormente invitado varias veces a Ginebra para debatir y elaborar los derechos reservados a los pueblos autóctonos. Con este bagaje a cuestas, volvió Nieva en el 2002 a Amaicha en un contexto interno sumamente conflictivo. Aquel año estaba poniéndose en marcha un proyecto del Banco Mundial denominado «Desarrollo de Comunidades Indígenas» (DCI), un fondo para el desarrollo sustentable de varias comunidades indígenas de Argentina; Amaicha era una de las destinatarias. Para E. Nieva, en aquel contexto, era impensable que este dinero fuese administrado por M. Pastrana, teniendo en cuenta las acusaciones de malversación de fondos que sobre él pesaban. Para Nieva, M. Pastrana había perdido la «cosmovisión indígena» y por esa razón constituyó un espacio de contrapoder instaurando un «Consejo de Ancianos». En Amaicha y en otros pueblos de la zona en donde se desarrollaban distintos conflictos agrarios, E. Nieva comenzó a dar «talleres de identidad». El objetivo era enseñar a la gente el lenguaje identitario de contestación que se desarrollaba sobre la escena internacional. Su meta era valorar la identidad indígena tan estigmatizada a nivel local, difundir los derechos en favor de los pueblos originarios. Su estatus de

12 El apoyo de una parte de los comuneros de Amaicha puede explicarse también gracias a los numerosos empleos públicos que Miguel Pastrana distribuyó durante sus gestiones como delegado comunal (cf. Isla 2002, Boullosa 2006). 
abogado daba a Nieva mucha legitimidad y mucho poder. Era él quien conocía el derecho y las nuevas leyes en favor de una población hasta ahora tan marginalizada. Era él quien podía defender las tierras en Amaicha, pero también en los alrededores. Nieva fue uno de los actores centrales en el proceso de etnización de las demandas sociales en el valle Calchaquí a principio de la década de 2000. No es un dato menor que, en el 2002, se haya constituido la Unión de Pueblos de Nación Diaguita, con 22 nuevas comunidades que reclamaron el estatus de comunidad indígena. En definitiva, su formación de abogado, en Buenos Aires y a nivel internacional, le sirvió para defender derechos locales y destituir a Miguel Pastrana en el 2002, radicándose definitivamente en Amaicha a partir de 2005 y siendo elegido como cacique en 2008.

Como puede desprenderse de lo dicho hasta el momento, las habilidades de estos líderes (sus conocimientos legales, la cercanía con las letras y el papel) se sostienen, a nuestro entender, en trayectorias personales previas que los ubican como personas políticamente activas y que, además, supieron tejer redes de relaciones a distintos niveles. Lógicamente, es menor la información que tenemos respecto de Olivares o de Juan Pablo Pastrana pero vale la pena agregar algunos aspectos sobre ellos. Un dato interesante es que tanto Olivares como Juan Pablo Pastrana no eran oriundos de Amaicha del Valle. En el primer caso, hemos comprobado que tanto él como su familia serían originarios de Atacama y que habrían arribado a Amaicha en la segunda mitad del siglo XVIII. Así, al menos, nos lo demuestran distintas inscripciones del archivo parroquial local ${ }^{13}$ y el hecho de que Olivares y su familia fueran registrados por primera vez en las revisitas de indios recién en el año 1792 (AGN, 1792, Revisita de San Miguel de Tucumán, fs. 37r.-38v). Si bien no tenemos datos precisos sobre don Lorenzo respecto a su vida antes de llegar a Amaicha, es posible imaginar que habrán pesado sus experiencias anteriores como parte de un colectivo que, como han mostrado varios autores, supieron rearticular una identidad colectiva a través de la implementación de estrategias de supervivencia variadas durante la colonia. Por otra parte, el hecho de haberse desempeñado como alcalde recaudador de tributo seguramente nutrió sus experiencias, siendo esta designación tanto resultado de ciertas aptitudes previas de Olivares como una ocasión para renovar o entablar contactos.

En el caso de Juan Pablo Pastrana, tampoco disponemos de muchos datos documentales. Sus actuales descendientes afirman que habría nacido en Molinos o en San Carlos (provincia de Salta) y que habría sido «guardaespaldas» del caudillo Felipe Varela en su lucha contra el centralismo porteño en la década de 1860. Justamente por su experiencia junto a Varela, por su valentía, es que la comunidad le habría solicitado interviniera en el conflicto territorial: «a él [J. P. Pastrana] lo hablan para que traiga la famosa cédula real ... y el pueblo lo habla a él porque él era, él tenía mucho coraje y sabían, lo conocían como era de peleador, que se podía defender, porque toda la gente, los caciques o las personas que iban no volvían más porque los mataban en el camino de ida y de vuelta» (Daniela Pastrana, enero de 2013).

13 APSM, Bautismo y Óleo de Naturales, Libro de Bautismos, 1780-1794, Tomo I, fs. 70r., 79v., 91v., 99r., 106r; APSM, Entierro de Naturales, Libro de Bautismos, 1780-1794, Tomo I, f. 136v.; APSM, Casamientos de Naturales, Libro de Bautismos, 1780-1794, Tomo I, f. 115r; APSM, Bautismo y Óleo de Naturales, Libro de Bautismos, 1780-1794, Tomo I, fs. 97r., 103v., 106r. En casi todos los casos, los curas de Santa María anotaron claramente que se trataba de «indios atacamas», «indios de la provincia de atacama», o «indios de Atacama». 
Disponemos, en cambio y como hemos visto ya, de datos más precisos respecto a las trayectorias seguidas tanto por Miguel Pastrana como por Eduardo Nieva. En el caso del primero, antes de acceder al cargo de delegado comunal y después de cacique, tuvo una larga experiencia urbana en San Miguel de Tucumán. Allí empezó su aprendizaje de «passeur culturel» y desarrolló una cierta habilidad para comunicarse con distintos «mundos» (rural y urbano). Después, su larga experiencia de delegado gremial, sus viajes y su militancia en el partido peronista fueron importantes también en su formación política. Nieva, algunas décadas después, completó una formación universitaria en derecho y adquirió una experiencia internacional que le dio una legitimidad innegable en su rol de contestación y de defensa de derechos específicos.

En relación a estos cuatro líderes, podemos decir que son personas que tienen disposiciones para ocupar puestos de poder, representar al pueblo y defender el territorio y sus derechos. Es interesante notar que en la base de su formación o trayectorias personales se encuentran distintos viajes: Olivares de Atacama a Calchaquí, Juan Pablo Pastrana de Molinos a Amaicha y a distintos lugares del NOA siguiendo a Felipe Varela, Miguel Pastrana de Santa María a Amaicha, luego a San Miguel de Tucumán y de vuelta a Amaicha, Eduardo Nieva de Amaicha a Santa María, a Buenos Aires, a Washington. Estos viajes previos, de formación personal podríamos decir, fueron moldeando la personalidad de estos líderes pero, probablemente, fueron los viajes realizados en pos del bienestar colectivo, los que terminaron de forjar su poder político, económico y simbólico. El hecho en sí de viajar, a las capitales virreinales, a las sedes de los gobiernos nacionales o los puntos internacionales del derecho indígena, se transforma en una hazaña, reconocida incluso con el otorgamiento de beneficios materiales (como en el caso de Juan Pablo Pastrana que habría recibido en recompensa una porción de terreno en El Paraíso), que no sólo imbuye de poder simbólico a quien la realiza, sino que también le permite entablar contactos, relaciones de distinto orden. En el caso de M. Pastrana y de E. Nieva, no sabemos si obtuvieron retribuciones concretas de parte de la comunidad, pero es posible pensar que se beneficiaron de lo que Gaxie (2005) llama las «retribuciones del militantismo»: un reconocimiento exterior y local, una valorización de sí mismo, el sentimiento de luchar para una causa justa, la posibilidad de viajar más todavía y una apertura mayor que pueden dar esos contactos externos. No se sabe si obtuvieron beneficios económicos de su lucha, pero lo cierto es que sus logros les dieron una posición de poder importante en la comunidad.

Por otra parte, y en muchos casos como resultado de los viajes, se alcanzan ciertos logros para la comunidad. Por ejemplo, se obtienen papeles que apuntan a resguardar el bien preciado de la tierra (cédulas reales, declaraciones del gobierno nacional, personerías jurídicas), recursos estatales (empleos públicos) y recursos económicos del Fondo Monetario Internacional, el Banco Interamericano de Desarrollo, The United Nations Children's Fund-UNICEF orientados a fomentar el desarrollo de proyectos colectivos (riego, educación, etc.). En una reunión pública en 2002, en plena crisis económica y política del país y en el pueblo con la polémica de la futura gestión de los fondos del DCI (Banco Mundial), M. Pastrana decía que era gracias a él y a su viaje a Naciones Unidas que Amaicha había resultado beneficiaria del importante proyecto de desarrollo. No se sabe cuánto se condicen esas afirmaciones con la realidad, pero lo cierto es que esos lazos externos trazados por M. Pastrana dieron a Amaicha una 
gran visibilidad y la posibilidad de captación de recursos para la comunidad. Esa habilidad de obtener recursos colectivos es importante también para sentar el poder de esos líderes. E. Nieva, por su lado, nos explicaba en una entrevista en el 2013 que los numerosos proyectos y fondos de parte de UNICEF para Amaicha eran resultado de sus relaciones anteriores cuando iba seguido a las Naciones Unidas.

Más allá de los recursos materiales que se obtienen y que, sin duda, recolocan en un lugar de privilegio al «viajero-intermediario», es posible pensar en las contribuciones simbólicas para el colectivo que resultan de las gestiones de los líderes en sus desplazamientos. Como hemos visto especialmente en el caso de Olivares y Juan P. Pastrana, los viajes -en tanto hazaña- se transforman en mojones temporales de la memoria colectiva que, recordados y reelaborados a lo largo del tiempo, acompañan las reclamaciones y defensas del territorio así como la reconstrucción de la identidad colectiva en torno al mismo. Para los viajes de los últimos líderes, no se sabe bien de qué manera van a integrar la memoria colectiva. Será necesario investigar dentro de algunas décadas para averiguarlo. Pero, en principio, los trámites que M. Pastrana hizo para «asegurar las tierras» son ya importantes en la memoria de ciertos ancianos que lo siguen apoyando.

Ahora bien, y para cerrar este apartado, quisiéramos señalar un aspecto más que los viajes pueden conllevar: su costado «problemático». Para volver al caso de Miguel Pastrana, si algunos vieron sus viajes como una prueba de heroísmo, sus oponentes los interpretaron de un modo diferente. Un testimonio de una amaicheña de 55 años evoca el viaje de Pastrana en 1998 a las Naciones Unidas para participar en los grupos de trabajo para los pueblos autóctonos en términos sorprendentes:

«Yo hoy entiendo que Miguel Pastrana es un cacique vitalicio, él ha hecho en el pueblo, aquí en Tucumán, lo ha hecho en Buenos Aires y lo ha hecho en las Naciones Unidas. A él, ¿quién lo va a sacar del pueblo como cacique vitalicio? Nadie. Y yo se lo digo a ustedes y espero que algún día has visto que vos te has equivocado y has dicho ¿no lo vamos a sacar? Porque él está como cacique de la comunidad indígena de los valles calchaquí en esa asamblea que ha habido en no sé qué parte del planeta, pero no es aquí en Argentina, él se ha ido y ha ido...yo no sé si en el Salvador, no sé y ahí ha estado con un grupo de caciques que manejan el mundo, y él está cacique vitalicio de los valles» (noviembre de 2002).

Nuestra entrevistada sitúa el viaje más allá de la Argentina, en una zona geográfica lejana. Se equivoca al ubicar a las Naciones Unidas en el Salvador en vez de en Ginebra, pero lo asocia a un lugar donde un grupo de caciques dirigen el mundo. La cita muestra que esos grandes lugares de defensa de derechos para beneficiar a las poblaciones discriminadas pueden ser vistos de manera muy distinta por los lugareños. Según la entrevistada, ese reconocimiento exterior desde tan lejos y ese papel de «cacique de los valles Calchaquíes» en un lugar donde «los caciques dirigen el mundo» daría a Miguel Pastrana una legitimidad impuesta desde el exterior, un poder en contra del cual los lugareños serían impotentes. Es decir, los lazos externos, reales o supuestos, pueden otorgar autoridad a quien los teje pero, también, los viajes de los líderes pueden no ser comprendidos y vistos por los lugareños, especialmente por parte de sus oponentes políticos, como sospechosos, un mero espacio de reproducción individual de poder, muy alejado de la defensa de los derechos e intereses del colectivo. 


\section{Palabras finales}

En el desarrollo de este trabajo hemos acompañado a cuatro autoridades étnicas de la Comunidad Indígena de Amaicha de Valle en los diferentes viajes que realizaron en distintas coyunturas históricas, en su mayoría, con el propósito de representar al colectivo. Como hemos visto, esos viajes y esa representación, si bien adquieren características particulares según el contexto histórico, en muchos casos están relacionadas con un aspecto fundamental: asegurar la tenencia colectiva de la tierra. De lo analizado en este artículo, podemos afirmar que no cualquiera podía realizar esos viajes. El seguimiento de las trayectorias personales de las figuras de autoridad aquí descriptas nos permite trazar entre ellos algunas similitudes. En primer lugar, en la base de su formación se encuentran distintos viajes y/o estadías urbanas que muy probablemente marcaron sus destinos. En segundo lugar, se trata de personas que fueron construyendo experiencias políticas de diverso orden, que manejaban el recurso de la palabra y la escritura y que conocían los resortes legales del momento. En tercer lugar, es interesante notar que estas figuras parecen moverse entre varios universos $\mathrm{y}$, especialmente en el ámbito local, en una «doble legitimidad»: dentro de la esfera estatal y dentro de la esfera de la comunidad. El caso más claro es el de Miguel Pastrana quien ocupó durante varios años y en forma paralela tanto el cargo de delegado comunal como el de cacique de la comunidad. Pero esto podría extenderse también al resto de las autoridades aquí analizadas: Olivares había sido designado por las autoridades coloniales como cobrador del tributo y, paralelamente, realizaba gestiones para defender las tierras colectivas; Juan Pablo Pastrana era apoderado de la comunidad pero también llegó a desempeñarse como juez de paz de Amaicha ${ }^{14}$; Eduardo Nieva, el actual cacique de la comunidad, y más allá de las funciones que ha desempeñado en la esfera internacional, se ha presentado a las últimas elecciones de delegado de la comuna (que finalmente ganó M. Pastrana).

Ahora bien, más allá de las semejanzas entre estas figuras, sus viajes y derroteros, es posible vislumbrar diferencias. Algunas obvias asociadas al contexto histórico (como por ejemplo el destino al que se trasladan: capital virreinal, sede del gobierno nacional o provincial, epicentro del derecho internacional). Otras que remiten a las historias de vida de cada una de las figuras analizadas. Al respecto Olivares y J. P. Pastrana se diferencian de M. Pastrana y de E. Nieva porque los dos primeros parecen ser «foráneos» que en determinado momento lograron «integrarse» al colectivo, mientras que los últimos son comuneros por descendencia, aunque con una formación desde la infancia-adolescencia fuera de Amaicha (un tema que, sin duda, nos remite a la cuestión de los límites de la comunidad, de los significados de la misma).

\footnotetext{
14 Según Steiman (2013), en la primera mitad del siglo XX, ya otros caciques ocuparon el cargo de juez de paz en Amaicha del Valle. Este tema de la doble legitimidad o doble juego necesita ser profundizado (un aporte fundamental al respecto puede encontrarse en Isla 2002). En principio, puede decirse que habría funcionado como una suerte de estrategia colectiva. Bengoa, en un texto que refiere a una nueva etapa de la emergencia indígena en esta última década, señala que «en esta nueva fase de descolonización, los indígenas buscarán apropiarse como ciudadanos étnicos de los instrumentos e instituciones del Estado y no retraerse a sus comunidades originarias en una suerte de repliegue o de 'auto apartheid'» (2009: 7). Desde este marco, el caso de Amaicha y las imbricaciones - aparentemente de larga data- entre Estado y comunidad podría resultar paradigmático.
} 
Finalmente, existen otras diferencias que podrían estar asociadas exclusivamente a una cuestión metodológica y a las fuentes por nosotras utilizadas. Por ejemplo, mientras los viajes realizados por Olivares y Juan Pablo Pastrana aparecen en la documentación consultada como hazañas llevadas a cabo casi por héroes impolutos, sin conflictos aparentes en el interior de la comunidad, en el caso de las autoridades más contemporáneas emerge el carácter sospechoso del viaje y también de los viajeros.

Esta cuestión acerca de lo metodológico es nodal y la señalamos someramente aquí como cierre de este artículo. La utilización de fuentes diferentes, las históricas y las etnográficas, nos plantean claramente una serie de desafíos. No todos los aspectos de la problemática pueden tratarse con la misma profundidad. Como hemos señalado, los documentos quizás no nos permiten ver algunos temas -como por ejemplo los conflictos internos que probablemente existieron alrededor de Olivares y J.P. Pastrana- pero sí otros. En tal sentido, a través de las fuentes históricas, podemos acercarnos al trabajo de la memoria, a los distintos caminos y bifurcaciones que toma en la larga duración $\mathrm{y}$, por ende, comprender mejor lo que ocurre en el presente. Las fuentes etnográficas, por su parte, construidas por nosotras mismas, nos permiten indagar en profundidad en algunos aspectos, preguntar y repreguntar, recuperar diferentes voces. Pero también nos enfrentan a lo coyuntural, a situaciones conflictivas puntuales en las que muchas veces se espera que nosotros participemos, situaciones que, a su vez, obturan las posibilidades de indagación y que, por supuesto, nos plantean una serie de cuestionamientos éticos acerca de nuestro rol y la forma en que tratamos la información recabada. Creemos, igualmente, que vale la pena tomar el desafío de realizar una investigación desde una perspectiva de larga duración e interdisciplinaria. Hemos intentado hacerlo en este trabajo a través de los viajes, los intermediarios culturales, sus trayectorias de poder y las negociaciones y gestiones desplegadas en torno a la tierra colectiva en Amaicha del Valle. Nos queda, sin duda, un largo camino por recorrer.

\section{Referencias documentales}

AGN (Archivo General de la Nación, Argentina)

1792, Revisita de San Miguel de Tucumán, 1792, Sala XIII, 17-2-1, Leg. 2, Libro 6.

AGPt (Archivo General de la Provincia de Tucumán)

1892, Protocolo 36, Tomo 33, Serie C.

AHT (Archivo Histórico de la Provincia de Tucumán)

1796, 16 de marzo, SA, Vol. 11.

1845, 21 de mayo, SJC, Serie A, Caja 82, Expte. 31.

1845, SJC, Serie A, Caja 82, Expte. 3.

1857, SJC, Caja 276, Expte. 274.

1872, SA, Tomo Tercero, vol. 119.

1881, SA, Vol. 150, Tomo VI.

1882, 14 de marzo, SJC, Caja 177, Expte. 12.

APSM (Archivo Parroquial de Santa María)

Bautismo y Óleo de Naturales, Libro de Bautismos, 1780-1794, Tomo I.

Casamientos de Naturales, Libro de Bautismos, 1780-1794, Tomo I.

Entierro de Naturales, Libro de Bautismos, 1780-1794, Tomo I. 


\section{Referencias bibliográficas}

Ardiles Gray, Julio

1971 [Entrevista a don Marcos Juan Rodríguez Espada]. La Opinión Literaria, 5 de septiembre.

Ares QueIJA, Berta y Serge GruZINSKI (coords.)

1997 Entre dos mundos. Fronteras culturales y agentes mediadores. Sevilla: Escuela de Estudios Hispano-Americanos.

BENGOA, José

2009 «Una segunda etapa de la Emergencia Indígena en América Latina?». Cuadernos de Antropología Social 29: 7-22.

Boullosa-Joly, Maité

2006 Re-devenir indien en Argentine - Amaicha et Quilmes à l'aube du XXIème siècle. Tesis doctoral inédita. París: École des Hautes Études en Sciences Sociales.

CRUZ, Rodolfo

1990-92 «La ‘construcción’ de identidades étnicas en el Tucumán Colonial: los Amaichas y los Tafíes en el debate sobre su 'verdadera' estructuración étnica». Relaciones de la Sociedad Argentina de Antropología 17: 65-92.

1997 «El fin de la ociosa libertad. Calchaquíes desnaturalizados a la jurisdicción de San Miguel de Tucumán en la segunda mitad del siglo XVII», en El Tucumán Colonial y Charcas, tomo 2, A. M. Lorandi, comp., pp. 215-264. Buenos Aires: Universidad de Buenos Aires.

s.f. «La evolución de la propiedad comunal de los calchaquíes desnaturalizados a la jurisdicción de San Felipe de Salta y San Miguel de Tucumán (1660-1800)». Ms.

GaXIE, Daniel

2005 «Rétributions du militantisme et paradoxes de l'action collective». Swiss Political Science Review 11 (1): 157-188.

IsLA, Alejandro

2002 Los usos politicos de la identidad. Indigenismo y Estado. Buenos Aires: Editorial de las Ciencias.

LoRANDi, Ana María y Roxana BoIXAdós

1987-88 «Etnohistoria de los valles Calchaquíes, siglos XVI y XVII». Runa 17-18: 263419.

Martínez Mauri, Mónica

2003 Médiation et développement, l'émergence des ONG et des passeurs culturels à Kuna Yala (Panama). Collection Itinéraires, 16. Ginebra: Publications de l'IUED.

Mendieta Parada, Pilar

2006 «Caminantes entre dos mundos: los apoderados indígenas en Bolivia (siglo XIX)». Revista de Indias 66 (238): 761-782.

Olivier de SARDAn, Jean-Pierre

1995 Anthropologie et développement. París: Ed. Karthala.

Pacheco de Oliveira, João

1998 «Uma etnologia dos 'indios misturados’? Situação colonial. Territorializaçao e fluxos culturais». Mana 4 (1): 47-77. 
Rivolta, Gustavo

1999 «Investigaciones preliminares en el sitio arqueológico Los Cardones, Pcia. de Tucumán», en Actas del XII Congreso Nacional de Arqueología Argentina, C. Diez Marín, ed., Tomo 3, pp. 340-344. La Plata: Facultad de Ciencias Naturales y Museo.

RODRÍGUEZ, Lorena

2009 «Los usos del sistema judicial, la retórica y la violencia en torno a un reclamo sobre tierras comunales. Amaicha del Valle, siglo XIX». Runa 30 (2): 135-150.

2010 "'Informar si el padrón que rige se conocen dos pueblos de indios de amaicha'. Re-estructuraciones socio-étnicas y disputas por tierras entre la colonia y la república». Memoria Americana. Cuadernos de Etnohistoria 18 (2): 267-292.

SOMOnTE, Carolina

2004 «Uso del espacio y producción lítica en Amaicha del Valle (Departamento Tafí del Valle, Tucumán)». Intersecciones en Antropología 6: 43-58.

SosA, Jorge

1999 «Teleprospección arqueológica en Amaicha del Valle (Departamento de Tafí del Valle, Tucumán)», en Actas del XII Congreso Nacional de Arqueología Argenitna, C. Diez Marín, ed., Tomo 3, pp. 358-365. La Plata: Facultad de Ciencias Naturales y Museo.

SosA, Jorge y Diana LeNTON

2009 «Oralidad, territorialidad y etnogénesis de un pueblo originario: la Cédula Real de Amaycha», en Arqueología, tierras y territorios: conflictos e intereses, Bárbara Manasse y Patricia Arenas, comps., pp. 53-74. San Miguel de Tucumán: Editorial Lucrecia.

Steiman, Ana Laura

2011 «Detrás de lo criollo. Tensiones clasificatorias sobre lo indígena en Amaicha del Valle. Primeras décadas del siglo XX», en Resistencias, conflictos y negociaciones. El valle Calchaqui desde el período prehispánico hasta la actualidad, Lorena Rodríguez, comp., pp. 145-170. Rosario: Prohistoria.

2013 «Estado y Comunidad en Amaicha del Valle, Tucumán: primera mitad del siglo $\mathrm{XX} »$. Ms.

TELL, Sonia

2010 «Expansión urbana sobre tierras indígenas. El pueblo de La Toma en la Real Audiencia de Buenos Aires». Mundo Agrario 10 (20). Documento electrónico, http://www.mundoagrario.unlp.edu.ar/article/view/v10n20a09/457, con acceso el $10 / 12 / 2014$.

WACHTEL, Nathan

2001 El regreso de los antepasados. Los indios urus de Bolivia del siglo XX al XVI. Ensayo de historia regresiva. México D.F.: Fondo de Cultura Económica. 